\title{
Coagulase negative staphylococci in Anti-Cancer Center, Batna, Algeria: antibiotic resistance pattern, biofilm formation, and detection of mecA and icaAD genes
}

\author{
${ }^{1 *}$ Zatout, A., ${ }^{2}$ Djibaoui, R., ${ }^{2}$ Kassah-Laouar, A., and ${ }^{3}$ Benbrahim, C. \\ ${ }^{1}$ Laboratory of Microbiology and Plant Biology, Department of Biological Sciences, Faculty of Natural Sciences \\ and Life, University of Abdlhamid Ibn Badis, Mostaganem, Algeria \\ ${ }^{2}$ Central Laboratory of Biology, Anticancer Center of Batna, Algeria \\ ${ }^{3}$ Laboratory of Microbiology Applied to the Agroalimentary Biomedical and the Environment, Department of \\ Biology, Faculty of Natural Sciences and Life, University Abou BekrBelkaid, Tlemcen, Algeria \\ *Correspondence to: asma.zatout@univ-mosta.dz
}

\begin{abstract}
:
Background: Coagulase-negative staphylococci (CoNS) are normal microbial flora found on the skin and mucous membranes of mammals. Considered for a long time as avirulent commensals, these bacteria are now recognized as opportunistic pathogens by virtue of their high resistance to multiple antibiotics and capacity for biofilm formations, which made them important agents of nosocomial and community-acquired infections. The objectives of this study are to determine the antibiotic resistance pattern and biofilm formation, and to detect $m e c A$ and icaAD genes in clinical CoNS isolates from Batna's Anti-Cancer Center (ACC) in Algeria.

Methods: A total of 66 CoNS were isolated from different samples and identified by API Staph system. In vitro antibiotic susceptibility testing (AST) of each isolate to selected antibiotics was determined by the disk diffusion method, and minimum inhibitory concentrations (MICs) of oxacillin and vancomycin were determined by E-test. Biofilm formation was assessed by Tissue Culture Plate (TCP) and Congo Red Agar (CRA) methods. The polymerase chain reaction (PCR) was used to amplify mecA gene in 9 oxacillin-resistant and 1 oxacillinsensitive CoNS, and icaAD gene in 9 biofilm forming and 1 non-biofilm forming CoNS. Sequencing of the $16 \mathrm{~S}$ rDNA of 1 mecA and 1 icaAD positive isolates was performed by the Sanger method.

Results: Nine species of CoNS were identified, with Staphylococcus epidermidis $(n=29,44 \%)$ and Staphylococcus haemolyticus $(n=15,22.7 \%)$ constituting the largest proportion, and isolated mainly from the onco-haematology service unit of the center. The isolates were resistant to penicillin $G(98.5 \%)$, cefoxitin $(80.3 \%)$ and oxacillin (72.2\%). The TCP method was more sensitive $(89.4 \%)$ than CRA method (31.8\%) in detecting biofilm formation. The mecA gene was detected in $66.7 \%(6 / 9)$ of oxacillin resistant CoNS and the icaAD gene in $55.6 \%(5 / 9)$ of TCP positive CoNS isolates

Conclusion: Invitro resistance to methicillin (oxacillin) and biofilm formation were high among the CoNS isolates in this study, but the association of these with respective carriage of mecA and icaAD genes was low.

Keywords: Coagulase negative staphylococci, identification, antibiotic resistance, biofilm, PCR

Received April 26, 2019; Revised October 2, 2019; Accepted October 5, 2019

Copyright 2020 AJCEM Open Access. This article is licensed and distributed under the terms of the Creative Commons Attrition 4.0 International License (http://creativecommmons.org/licenses/by/4.0), which permits unrestricted use, distribution and reproduction in any medium, provided credit is given to the original author(s) and the source.
\end{abstract}

\section{Staphylocoques à coagulase négative au Centre Anti-Cancer du Batna, Algérie: résistance aux antibiotiques, formation de biofilms et détection des gènes mecA et icaAD}

\footnotetext{
${ }^{1 *}$ Zatout, A., ${ }^{2}$ Djibaoui, R., ${ }^{2}$ Kassah-Laouar, A., et ${ }^{3}$ Benbrahim, C.

${ }^{1}$ Laboratoire de Microbiologie et Biologie Végétale, Département des Sciences Biologiques, Faculté des Sciences de la Nature et de la Vie, Université Abdlhamid Ibn Badis, Mostaganem, Algérie

${ }^{2}$ Laboratoire Central de Biologie, Centre Anti-Cancer (ACC), Batna, Algérie

${ }^{3}$ laboratoire de Microbiologie Appliquée à I'Agroalimentaire au Biomédical et à I'Environnement, Département de Biologie, Faculté des Sciences de la Nature et de la Vie, Université Abou Bekr Belkaid, Tlemcen, Algérie

Correspondance à: asma.zatout@univ-mosta.dz
} 


\section{Abstrait :}

Contexte: Les staphylocoques à coagulase négative (CoNS) sont une flore microbienne normale présente sur la peau et les muqueuses humaines des mammifères. Considérés depuis longtemps comme des commensales avirulentes, ces bactéries sont reconnues comme agents pathogènes opportunistes grâce à leurs multiples propriétés coexistantes de résistance aux antibiotiques et de formation de biofilms qui constituent des agents importants d'infections nosocomiales et communautaires. l'objectif de cette étude est de déterminer la résistance aux antibiotiques, la formation de biofilms et pour rechercher des gènes mecA et icaAD dans les isolats cliniques de staphylocoques à coagulase négative du Centre Anti-Cancer (AAC) de Batna en Algérie. Méthodes: au total de 66 des SCN ont été isolés de différents prélèvements et identifiés par galerie API Staph. Le test de sensibilité aux antibiotiques In vitro de chaque isolat par rapport aux antibiotiques sélectionnés a été déterminé par la méthode de diffusion sur disque, et les concentrations minimales inhibitrices (MICs) de l'oxacilline et de la vancomycine ont été déterminées par E-test. La formation de biofilm a été évaluée par la méthode de culture de tissu en plaque (TCP) et la méthode de Rouge Congo Agar (CRA). La réaction en chaîne par polymérase (PCR) a été utilisée pour amplifier I'ADN du gène mecA dont 9 des SCN résistants à l'oxacilline et 1 sensible à l'oxacilline et le gène icaAD dont 9 des SCN formant biofilm et 1 non-formant biofilm. Le séquençage de I'ADNr $16 \mathrm{~S}$ des isolats positifs, $1 \mathrm{mec} A$ et 1 icaAD ont été réalisés par la méthode de Sanger. Résultats: Neuf espèces des SCN ont été identifiées avec Staphylococcus epidermidis $(n=29,44 \%)$ et Staphylococcus haemolyticus ( $n=15,22,7 \%$ ) constituant la plus grande proportion, et isolées principalement de I'unité de service d'onco-hématologie du centre. Les isolats étaient résistants à la pénicilline G $(98,5 \%)$, à la céfoxitine $(80,3 \%)$ et à l'oxacilline $(72,2 \%)$. La méthode TCP était plus sensible $(89,4 \%)$ que la méthode CRA $(31,8 \%)$ dans la détection de la formation de biofilm. Le gène mecA a été détecté dans $66,7 \%(6 / 9)$ des SCN résistants à l'oxacilline et le gène icaAD dans $55,6 \%(5 / 9)$ des isolats positifs des SCN pour CRA.

Conclusion: La résistance à la méthicilline (oxacilline) in vitro et la formation de biofilms étaient élevées chez les isolats des SCN de cette étude, mais leur corrélation avec le portage respectif des gènes mecA et icaAD était faible.

Mots-clés: Staphylocoque à coagulase négative, identification, résistance aux antibiotiques, biofilm, PCR

\section{Introduction:}

Coagulase negative staphylococci (CoNS) are normal microbial flora found on the skin and human mucous membranes of mammals (1). These bacteria, which have for a long time adjudged to be avirulent commensals, are currently considered the predominant pathogens (2) and major cause of nosocomial and community-acquired infections (3).

The most common species that cause disease in humans are Staphylococcus epidermidis which causes bacteremia in patients with implanted medical devices (such as prostheses and catheters), surgical wound infection, peritonitis in patients with continuous peritoneal dialysis, osteomyelitis, and endophthalmitis; Staphylococcus haemolyticus which causes endocarditis, peritonitis, sepsis and infections of the urinary tract, wounds, bones and joints; and Staphylococcus saprophyticus which causes urinary tract infections and septicemia. The other important opportunistic pathogenic species include Staphylococcus hominis, Staphylococcus warneri, Staphylococcus capitis, Staphylococcus simulans, Staphylococcus cohnii, Staphylococcus xylosus and Staphylococcus saccharolyticus (4).

The treatment of the infections by CoNS is difficult because many clinical isolates exhibit multiple and high resistance to antibiotics, leading to increased inefficiency of a wide range of antibiotics (5). There are several reports in literature showing high resistance to methicillin and other antibiotics among CoNS isolates $(6,7,8)$. Methicillin resistance in CoNS is caused by the $\operatorname{mec} A$ gene that encodes penicillin-binding protein $2 \mathrm{a}$ (PBP2a) that has low binding affinity to $\beta$ lactams $(2,9,10,11)$.

The ability to form biofilm is the most important virulence factor in CoNS, which facilitates its adhesion to and colonization of artificial materials (8). Bacteria in biofilms can resist antibiotics at concentrations up to 1000 times higher than those active on the same bacteria in the planktonic state (12). The biofilm consists of layers of cellular clusters integrated in a matrix of extracellular polysaccharide, called polysaccharide intracellular adhesion (PIA). The enzymes implied in the synthesis of PIA are encoded by the ica operon including the icaA, icaD, icaB and icaC genes (13).

The two common phenotypic methods for detecting biofilm formation, Tissue Culture Plate (TCP) and Congo Red Agar (CRA), were described by Christensen et al., (14) and Freeman et al., (15) respectively. Molecular detection of the icaAD locus was initially described by Heilmann, et al., (16) in $S$. epidermidis but few years later, its presence was confirmed in many other species of staphylococci isolated from implant relatedinfections (12). The objectives of this study are to evaluate antibiotic resistance and biofilm formation in CoNS isolated from patients at the Anti-Cancer Center of Batna, Algeria, and to detect the responsible mecA and $i c a A D$ genes in these isolates. 


\section{Materials and method:}

\section{Study setting and bacterial isolates}

This study was conducted at the Microbiology Laboratory of the Anti-Cancer Center (ACC), Batna, Algeria. Sixty six coagulase negative staphylococci (CoNS) were isolated from clinical samples (urinary probes, urine, blood culture, pus, wound, pleural fluid, cerebrospinal fluid, intravenous catheter, and drain) obtained from hospitalised patients in various service units (oncohaematology, onco-paediatric, intensive care and carcinological surgery) of the center and from outpatients, between $1^{\text {st }}$ of January and $30^{\text {th }}$ of June, 2017 . Duplicate samples were excluded.

The samples were cultured on Mannitol Salt (Chapman) agar and incubated at $37^{\circ} \mathrm{C}$ for 48 hours. All strains were identified by colony morphology, Gram stain reaction, catalase production, coagulase assay, and the API Staph system (bioMérieux, France). The purified isolates were stored at $4^{\circ} \mathrm{C}$.

Antibiotic susceptibility testing of isolates In vitro antibiotic susceptibility testing (AST) was performed by the disk diffusion test on Mueller-Hinton ( $\mathrm{MH}$ ) agar as described by Bauer et al., (17) and the interpretation of the results was done according to Clinical and Laboratory Standards Institute (CLSI) guidelines (18). All isolates were tested with the following antibiotics: penicillin (10 UI), cefoxitin $(30 \mu \mathrm{g})$, gentamicin $(10 \mu \mathrm{g})$, amikacin (30 $\mu \mathrm{g})$, kanamycin (30 $\mu \mathrm{g})$, erythromycin $(15 \mu \mathrm{g})$, tetracycline $(30 \mu \mathrm{g})$, ofloxacin (5 $\mu \mathrm{g})$, laevofloxacin (5 $\mu \mathrm{g})$, ciprofloxacin $(5 \mu \mathrm{g})$, clindamycin $(2 \mu \mathrm{g})$, chloramphenicol $(30 \mu \mathrm{g})$, rifampicin $(5 \mu \mathrm{g})$, trimethoprim/sulfamethoxazole $\quad(1.25 / 23.75$ $\mu \mathrm{g})$, fusidic acid $(10 \mu \mathrm{g})$, pristinamycin (15 $\mu \mathrm{g})$ and teicoplanin $(30 \mu \mathrm{g})$. The minimum inhibitory concentrations (MICs) of oxacillin and vancomycin for each isolate were determined on $\mathrm{MH}$ using E-test method, and results interpreted according to CLSI guidelines (18).

\section{Detection of biofilm formation by Congo Red Agar (CRA) method}

The qualitative determination of the biofilm formation was carried out by culturing CoNS isolates on Congo Red Agar as proposed by Freeman et al., (15). The prepared medium was inoculated with CoNS isolates and incubated at $37^{\circ} \mathrm{C}$ for 24 to 48 hours. Biofilm-forming bacteria appear black with a crystalline lens of dry consistency where the Congo Red dye interacts directly with certain bacterial polysaccharides forming a slime while the non-biofilm forming colonies remained red.
Detection of biofilm formation by Tissue Culture Plate (TCP) method

Quantitative determination of biofilm formation on microplates was evaluated as described by Christensen et al., (14) with some modifications. The microplates used were made of polystyrene with 96 wells on which the bacteria adhere and form biofilm. The isolates were cultivated on nutrient agar for $18-24$ hours at $37^{\circ} \mathrm{C}$. A colony of each isolate was inoculated into $5 \mathrm{ml}$ Trypticase Soy Broth (TSB) and incubated at $37^{\circ} \mathrm{C}$ for 24 hours, and the culture was then diluted $1: 100$ in the TSB $(+1 \%$ glucose $)$. Each well of the microplate was filled with $200 \mu \mathrm{L}$ of this dilution (three independent cultures for each isolate). A sterile broth of TSB ( $+1 \%$ glucose) was used as a negative control.

The microplates were sealed and incubated for 24 hours at $37^{\circ} \mathrm{C}$. Thereafter, the contents of the wells were gently removed and washed four times with sterile physiological water and then dried at $60^{\circ} \mathrm{C}$ for 30 minutes. The cells adhering to the polystyrene support in each of the wells were stained with $200 \mu$ l of $1 \%$ crystal violet (w/v) and incubated for 30 minutes following which excess crystal violet was removed by 5 successive washes with sterile distilled water and the plates dried at room temperature. The dye incorporated by the adhered cells was solubilized with $200 \mu \mathrm{L}$ of $95 \%$ ethanol $(\mathrm{v} / \mathrm{v})$.

The amount of dye solubilized was measured by reading the optical density (OD) at $550 \mathrm{~nm}$ using Bio-Rad ELISA reader (PR 3100 TSC) (19). The interpretation of the results was performed according to the criteria of Stepanovic et al., (20). The OD of the isolate was obtained by the arithmetic mean of three wells and this value was compared with the mean absorbance of negative control (ODc). The isolates were classified as non-biofilm producer (OD $\leq$ ODc), weak biofilm producer (ODc $<O D \leq 2$ ODc), moderate biofilm producer (2ODc $\angle O D \leq$ 4ODC) and strong biofilm producer (4ODc $<$ OD).

\section{Detection of mecA and icaAD genes by PCR and $16 s$ rDNA sequencing}

The PCR of mecA and icaAD genes and the sequencing of the $16 \mathrm{~S}$ rRNA genes were performed in the Laboratory of DIAGGENE, Angers, France. Nine MRCoNS strains (no 1 to 9) and 1 MSCoNS strain (no 10), were selected for $\operatorname{mec} A$ gene detection. Similarly, 9 biofilm-forming strains (no 11 to 19) and 1 non-biofilm forming strain (no. 20) were selected from the TCP results for icaAD gene detection.

\section{PCR assay}

The mecA and icaAD genes amplifications were performed by PCR as described by 
Poulsen et al., (21) and Yazdani et al., (22) respectively, using the following specific primers; mecA-F:5'-GGGATCATAGCGTCATTATTC-3' and mecA-R:5'-AACGATTGTGACACGATAGCC-3', icaAD-F: 5'-TATTCAATTTACAGTCGCAC-3' and icaAD-R: 5'-GATTCTCTCCCTCTCT GCCA-3'. The DNA amplification was done in a Mycycler thermal cycler (Bio-Rad, USA). The amplification products $(10 \mu \mathrm{L})$ were eletrophoresed on $1.5 \%$ agarose gel followed by staining in an ethidium bromide bath $(0.5 \mu \mathrm{g} / \mathrm{ml})$. The amplified DNA products were visualized under UV transillumination. Sequencing of the $16 S$ rRNA genes

Sequencing of amplified and purified $16 \mathrm{~S}$ rDNA of strain number $3(\operatorname{mec} A+)$ and strain number 13 (icaAD+) was performed as described by Sanger et al., (23), using the

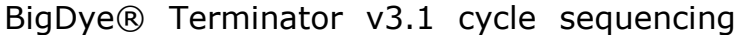
kit (Applied Biosystems, USA) and two universal primers (27F and 1492R). The $16 \mathrm{~S}$ sequences obtained were then compared with those of the GeneBank database using the BLAST programme (24).

\section{Results:}

\section{Identification of CoNS isolates}

Sixty six CoNS belonging to 9 different species were identified by the conventional methods; S. epidermidis 29, S. haemolyticus $15, S$. hominis $8, S$. chromogenes 6, S. xylosus 4, S. capitis 1, S. saprophyticus $1, S$. cohnii 1 , and S. simulans 1 (Table 1).

Table 1: Species distribution of CoNS isolates in Anti-Cancer Center, Batna, Algeria

\begin{tabular}{ccc}
\hline CoNS isolate & Frequency & Percentage \\
\hline Staphylococcus epidermidis & 29 & 43.9 \\
Staphylococcus haemolyticus & 15 & 22.7 \\
Staphylococcus hominis & 8 & 12.1 \\
Staphylococcus chromogenes & 6 & 9.1 \\
Staphylococcus xylosus & 4 & 6.1 \\
Staphylococcus capitis & 1 & 1.5 \\
Staphylococcus cohnii & 1 & 1.5 \\
Staphylococcus saprophyticus & 1 & 1.5 \\
Staphylococcus simulans & 1 & 1.5 \\
Total & 66 & 100 \\
\hline
\end{tabular}

Table 2 shows the distribution of the CoNS according to the clinical samples; 28 $(42.4 \%)$ were from blood cultures ( $S$. epidermidis 11,5 . haemolyticus 8,5 . hominis 8 and S. chromogenes 2); 13 (19.7\%) from catheter samples ( $S$. epidermidis $8, S$. haemolyticus 2, S. chromogenes 1 , S. xylosus 1 and $S$. capitis 1$) ; 8(12.1 \%)$ from pus samples (S. epidermidis 2, S. chromogenes 2, S. haemolyticus 1 , and S. xylosus 3 ); 6 $(9.1 \%)$ from urine samples (S. epidermidis 3, S. haemolyticus 2, and S. hominis 1 .

Table 2: Specimen distribution of CoNS isolates in Anti-Cancer Center, Batna, Algeria

\begin{tabular}{ccc}
\hline Samples & Frequency & Percentage \\
\hline Blood & 28 & 42.4 \\
Vascular catheter & 13 & 19.7 \\
Pus & 8 & 12.1 \\
Urine & 6 & 9.1 \\
CSF & 5 & 7.6 \\
Pleural fluid & 3 & 4.5 \\
Wound & 1 & 1.5 \\
Urinary probe & 1 & 1.5 \\
Drain & 1 & 1.5 \\
Total & 66 & 100 \\
\hline CoNS = coagulase negative staphylococci &
\end{tabular}

The CoNS isolates were found mainly in the onco-haematology service $(n=30$, $45.5 \%)$, out of which 13 were S. epidermidis (Table 3).

Table 3: Distribution of CoNS isolates by service unit in Anti-Cancer Center, Batna, Algeria

\begin{tabular}{ccc}
\hline Service unit & No of CoNS & Percentage \\
\hline Onco-haematology & 30 & 45.5 \\
Carcinological surgery & 14 & 21.2 \\
Onco-paediatric & 10 & 15.2 \\
Intensive care & 7 & 10.6 \\
Outpatient & 5 & 7.6 \\
Total & 66 & 100 \\
\hline CoNS = coagulase negative staphylococci
\end{tabular}

\section{Antimicrobial susceptibility profiles of CoNS isolates}

The AST profile of the isolates is detailed in Fig 1. The isolates exhibited high resistance to penicillin G $(98.5 \%)$, cefoxitin $(80.3 \%)$, oxacillin $(74.2 \%)$, fusidic acid $(60.6 \%)$, but were totally sensitive to chloramphenicol and vancomycin (by the E-test). The isolates were also largely sensitive to amikacin $(86.4 \%)$, teicoplanin $(83.3 \%)$ and tetracycline $(80.3 \%)$ but susceptibility was reduced to rifampicin $(71.2 \%)$, clindamycin $(69.7 \%)$, gentamicin $(68.2 \%)$, pristinamycin $(63.6 \%)$, ofloxacin $(63.6 \%)$, laevofloxacin $(62.1 \%)$, erythromycin $(50 \%)$ and kanamycin (45\%).

The most frequent CoNS isolates, $S$. epidermidis, was totally resistant to penicillin G $(100 \%), 69 \%$ to cefoxitin, and $60 \%$ to oxacillin by the E-test (Fig. 2). 


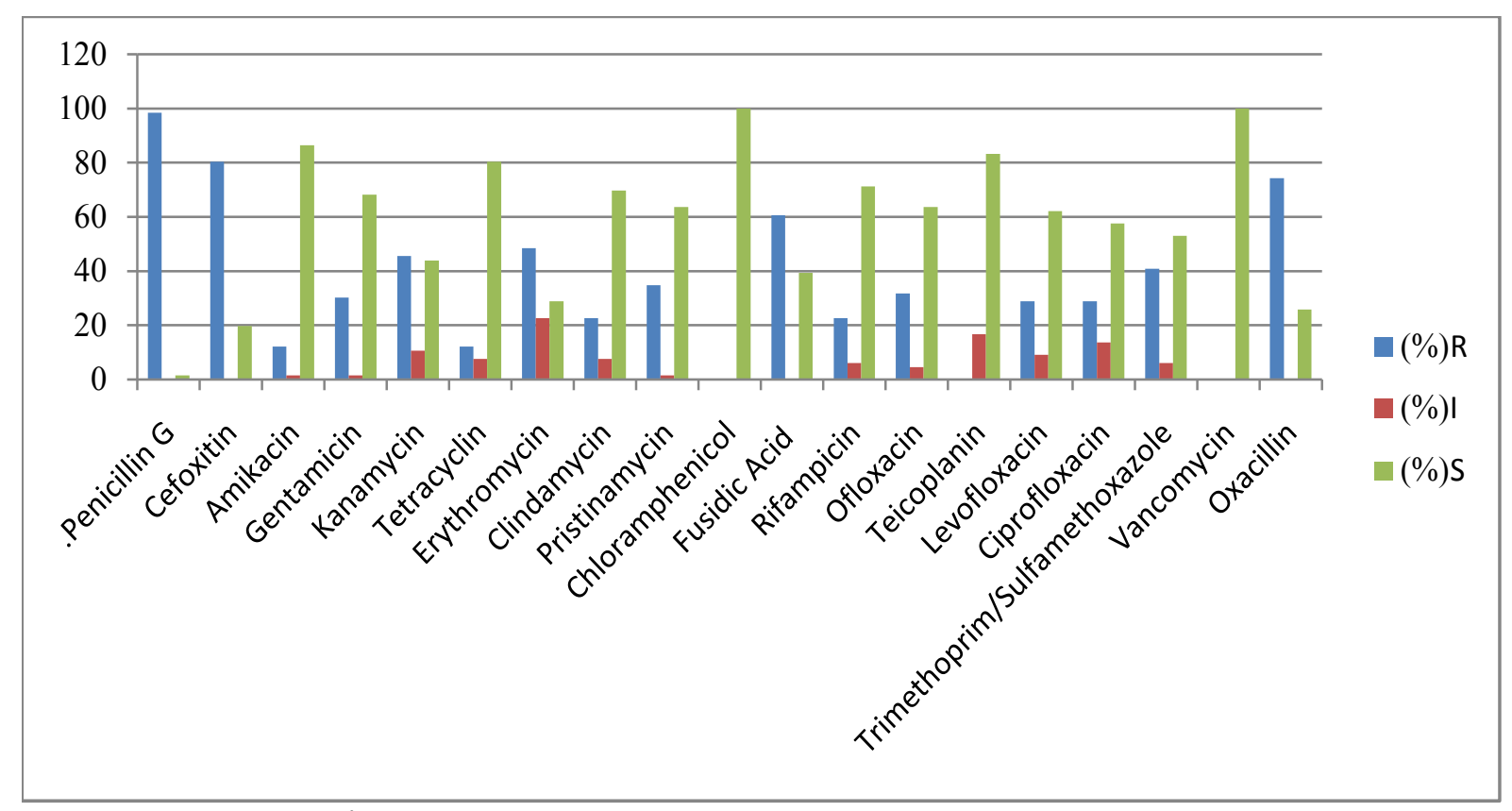

$\mathrm{R}=$ resistance; $\mathrm{I}=$ intermediate; $\mathrm{S}=$ sensitive

Fig 1: Antimicrobial susceptibility profiles of coagulase negative staphylococci isolates

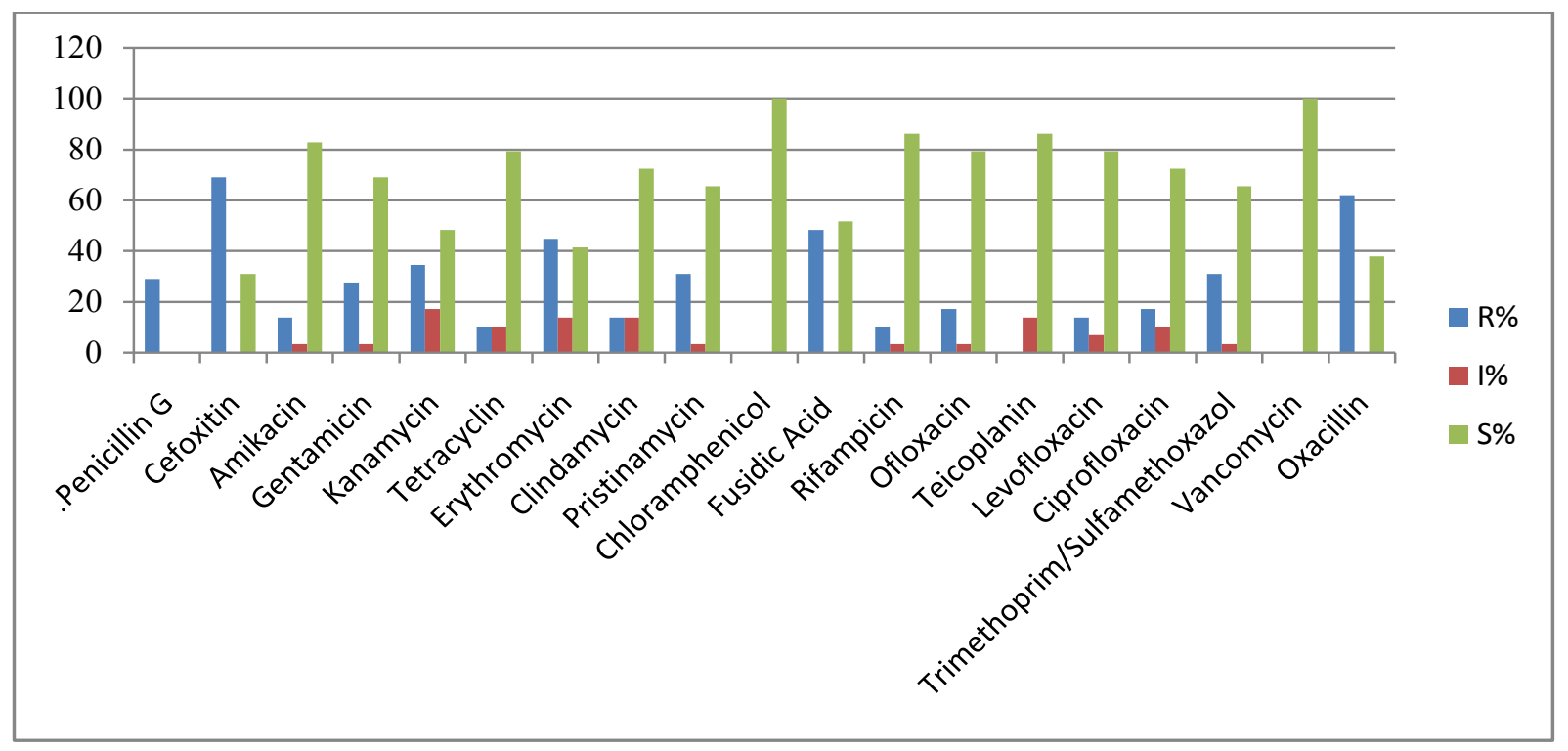

$\mathrm{R}=$ resistance; $\mathrm{I}=$ intermediate; $\mathrm{S}=$ sensitive

Fig 2: Antimicrobial susceptibility profiles of Staphylococcus epidermidis

\section{Biofilm formation}

Fig. 3 shows the result of biofilm formation by the CRA method with 21 (31.8\%) CoNS isolates forming biofilm while $45(68.2 \%)$ were negative. The results of biofilm formation by the TCP method showed that $59(89.4 \%)$ of the 66 isolates formed biofilms with different intensities (Fig 4); 16 $(24.2 \%)$ were strong biofilm forming, 23 $(34.9 \%)$ were moderate, $20(30.3 \%)$ were weak, and 7 (10.6\%) were non-biofilm forming bacteria. 


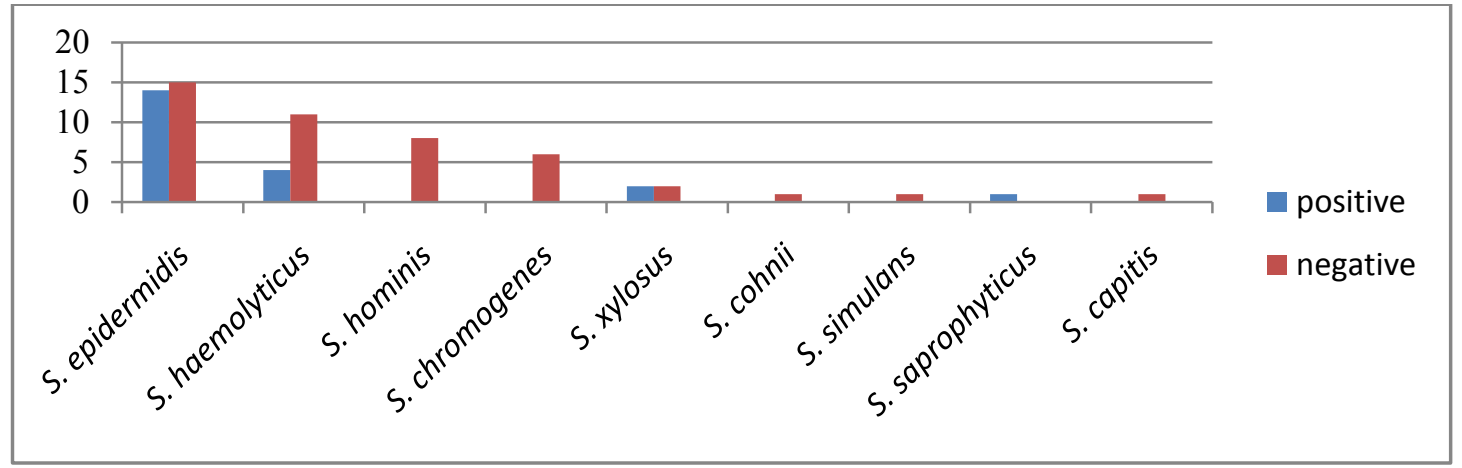

Fig 3: Biofilm formation tested by Congo Red Agar method

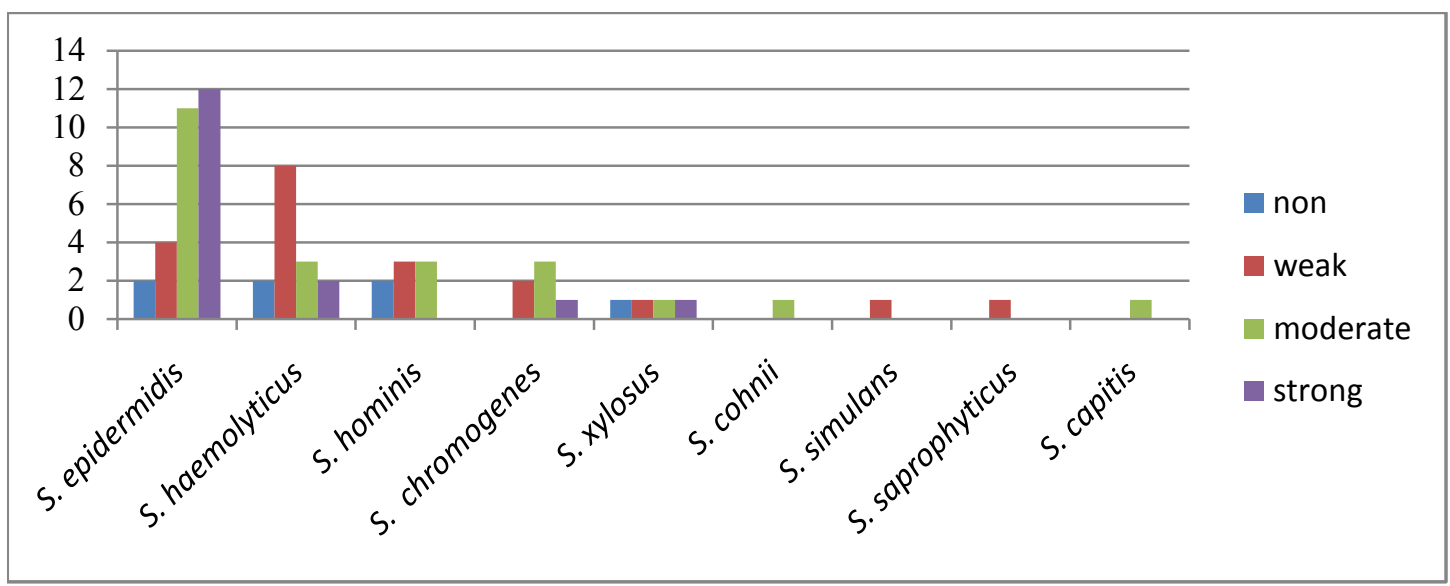

Fig 4: Biofilm formation tested by the Tissue Culture Plate method

\section{Result of mecA and icaAD genes PCR}

Of the 9 CoNS isolates resistant to oxacillin by the AST tested for carriage of mecA gene, only 6 amplified for the gene (Fig $5 a)$. Similarly, only 5 of the 9 CoNS isolates positive for biofilm production by the CRA method amplified for the icaAD genes (Fig $5 b)$. Sequencing of the $16 S$ rRNA genes of in each isolate positive for mecA and icaAD shows percentage similarity to respective GenBank strains as shown in Table 4.

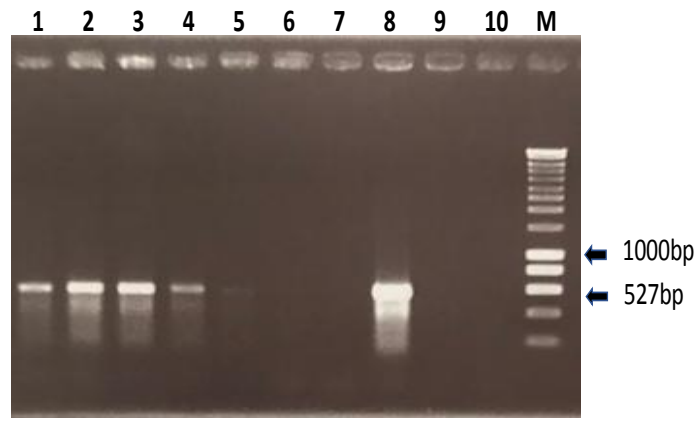

(a) mecA gene

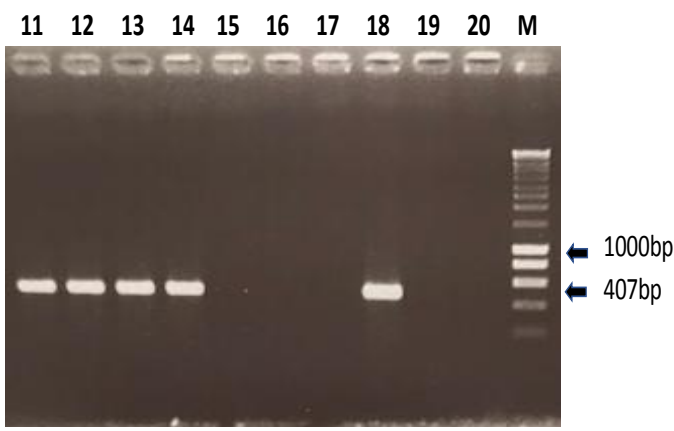

(b) icaAD gene

M: molecular size marker (Smart Ladder 200bp, Eurogentech); 1-9: MRCoNS; 10: MSCoNS; 11-19: TCP+ CoNS; TCP- CoNS

Fig 5: Agarose gel electrophoresis of mecA and icaAD genes 
Table 4: Percentage similarity of two CoNS isolates on BLAST analysis

\begin{tabular}{ccc}
\hline $\begin{array}{c}\text { Identification number }\left(\mathrm{N}^{\circ}\right) \\
\text { isolate }\end{array}$ & \%similarity to strain in GenBanl & Identification \\
\hline 3 & 100 & Staphylococcus haemolyticus strain FC2950 \\
13 & 100 & Staphylococcus epidermidis strain K121 \\
\hline
\end{tabular}

\section{Discussion:}

Our study identified 9 species out of the 66 CoNS characterized, with predominance of S. epidermidis (44\%), S. haemolyticus $(22.7 \%)$ and $S$. hominis $(12.1 \%)$. This similar pattern has been reported by Shah et al., (25) who reported $35.1 \%$ for $S$. epidermidis, $33.1 \%$ for $S$. saprophyticus and $8.8 \%$ for $S$. haemolyticus, as well as by many other researchers $(1,8,26,27)$. The CoNS in our study especially $S$. epidermidis were found in onco-haematology service unit mainly from blood cultures which is similar to what Marsik et al., reported in their study (28). CoNS is the most frequently isolated bacteria from blood cultures and is a serious health challenge in developing as well as in many developed countries (4). S. epidermidis is the most common species involved in blood stream infections, which is attributed to its ability to colonize central venous catheters and other implanted medical devices (29).

CoNS resistant to multiple antibiotics have become a great challenge in nosocomial infections. In this study, $80.3 \%$ of the CoNS isolates were methicillin resistant by the cefoxitin disk and $74.2 \%$ by the oxacillin Etest, and resistance to penicillin $G$ was $98.5 \%$. This high resistance rate to both methicillin and penicillin $G$ have been reported by several other researchers $(1,6,7,30,31,32)$. Methicillin resistance is usually associated with mecA gene that encodes abnormal penicillin binding protein PBP2a (PBP2a) with low binding affinity for $\beta$ lactam antibiotics (5). The mecA gene is located on a mobile genetic element, the staphylococcal cassette chromosome mec (SCCmec) which can be transferred between and within the staphylococcal species (33). MRSA isolates are usually not reliably detected by phenotypic techniques, especially as the expression of mecA gene varies according to strains, some of which may possess heterogeneous resistance, hence the need for genotypic characterization (34).

In our study, no CoNS isolates was resistant to vancomycin by the E-test MIC, which agrees with the reports of Jain et al., (35) and Shrestha et al., (1). Vancomycin and teicoplanin are anti-staphylococcal antibiotics to which resistance is rarely observed. These antibiotics should however be reserved for the treatment of staphylococcal infections resistant to all other antibiotics (32). The CoNS isolates were also largely sensitive to amikacin and tetracycline ( $>80 \%$ ) but susceptibility to fluoroquinolones (ofloxacin, ciprofloxacin and laevofloxacin), clindamycin, pristinamycin, erythromycin and trimethoprim/sulfamethoxazole were reduced with resistance rate being over $20 \%$ for each of these isolates. Our findings are similar to what others have reported for CoNS clinical isolates $(3,28,29,36,37,38)$.

The ability of staphylococci to form biofilms helps the bacterium to resist host immune response and is considered responsible for chronicity as biofilm protects microorganisms from opsono-phagocytosis and antimicrobial agents. In view of the large number of infections caused by biofilm producing bacteria, a reliable method for their diagnosis is necessary. Nasr et al., (39) reported that $50 \%$ of CoNS isolated from intravascular blood cultures and catheters were biofilm producers using the CRA method, which is higher than $31.8 \%$ reported in our current study. The TCP method has however been reported to be a more sensitive, accurate and reproducible screening method for detecting biofilm production in clinical staphylococci isolates with added advantage of being a quantitative tool for comparing the adherence of different strains (39). Oliveira et al., (26), Soumya et al., (8) and Shrestha et al., (1) reported that $73 \%$, $87.5 \%$ and $85 \%$ CoNS respectively produce biofilm by the TCP method. This is similar to the high rate of $89.4 \%$ reported in our current study.

The ability of CoNS to be resistant to methicillin and produce biofilm is an important factor in infectivity which occurs through expression of $\operatorname{mec} A$ and ica genes respectively. Jain et al., (35) have reported that detection of mecA gene by PCR can be a beneficial complement to standard susceptibility test that can allow the identification of intrinsic resistance quickly and efficiently, as most strains carry the classical mecA gene. Six of the $9(66.7 \%)$ selected CoNS isolates resistant to methicillin (by oxacillin E-test) in 
our study amplified for mecA gene. However, other allotypes of mecA gene, have been described for subspecies of $S$. sciuri (mecA1) and for $S$. vitulinus (mecA2) among animalderived isolates. Another mecC allotype, mecC2, was recently reported for methicillin resistant $S$. saprophyticus subsp. saprophyticus (40). The icaAD gene amplified in 5 of the $9(55.5 \%)$ selected CoNS isolates in our study. This rate is higher than the $32 \%$ reported by Nasr et al., (39). It has been reported that the icaAD gene is not always associated with in vitro biofilm formation (39). The biofilm-forming ability of some isolates in the absence of icaAD gene highlights the need to investigate the genetic basis of ica-independent biofilm formation.

\section{Conclusion:}

In vitro resistance to methicillin (oxacillin) and biofilm formation were high among the CoNS isolates in Anti-Cancer Center, Batna, Algeria, but the association of these phenotypes with respective carriage of mecA and icaAD genes was low. Further studies are needed to investigate the genetic basis of biofilm formation independent of ica $A D$ genes.

\section{References:}

1. Shrestha, L. B., Bhattarai, N. R., and Khanal, B. Antibiotic resistance and biofilm formation among coagulase-negative staphylococci isolated from clinical samples at a tertiary care hospital of eastern Nepal. Antimicrob Resist Infect Contr. 2017; 6 (89): 1-7.

2. Ahmed, R., Singh, $S$, Farooq, $U$, et al. Occurrence and Antimicrobial Susceptibility Pattern of Methicillin-resistant Staphylococcus aureus and Methicillin-resistant CoagulaseNegative Staphylococci Isolated from Different Clinical Specimens from the Patients Hospitalized in Teerthanker Mahaveer Medical College and Research Centre, Moradabad, India. Intern J. Sci Study. 2016; 3 (11): 41-47.

3. Cuevas, O., Cercenado, E., Vindel, A., et al. Evolution of the Antimicrobial Resistance of Staphylococcus spp. In Spain: Five Nationwide Prevalence Studies, 1986 to 2002. Antimicrob Agents Chemother. 2004; 48 (11): 4240-4245.

4. Cunha, Mde L., Sinzato, Y. K., and Silveira, L. V. A. Comparison of Methods for the Identification of Coagulase negative Staphylococci. Mem Inst Oswaldo Cruz. 2004; 99 (8): 855-860.

5. Xu, Z., Mkrtchyan, H. V., and Cutler, R. R. Antibiotic resistance and mecA characterization of coagulase-négtive stahylococci isolated from three hotels in London, UK. Front Microbiol.2015; 6: 1-6.

6. Koksal, F., Yasar, H., and Samasti, M. Antibiotic resistance patterns of coagulase negative Staphylococcus strains isolated from blood cultures of septicaemic patients in Turkey. Microbiol Res. 2009: 164: 404-410

7. Nagasrilatha, B., Manmohan, B., Sasidhar, M., et al. A Study on Methicillin Resistant Coagulase Negative Staphylococci Isolated from Medical Intensive Care Unit at a Tertiary Care CentreIndia". Journal of Evolution of Medical and Dental Sciences. 2015; 4 (61): 10597-10601.
8. Soumya, K. R., Philip, S., Sugathan, S., et al. Virulence factors associated with Coagulase Negative Staphylococci isolated from human infections. Biotechnol. 2017; 7 (14): 1 - 10 Hanssen, A. M., Kjeldsen, G., and Sollid, J. U. E. Local Variants of Staphylococcal Cassette Chromosome mec in Sporadic MethicillinResistant Staphylococcus aureus and MethicillinResistant Coagulase-Negative Staphylococci: Evidence of Horizontal Gene Transfer? Antimicrob Agents Chemother. 2004; 285: 296

10. Zong, Z., Peng, C., and Lu, X. Diversity of SCCmec Elements in Methicillin-Resistant Coagulase-Negative Staphylococci Clinical Isolates. PLoS One. 2011; 6 (5): 1-6.

11. Bhatt, P., Tandel, K., Singh, A., et al. Prevalence and molecular characterization of methicillin resistance among Coagulase-negative Staphylococci at a tertiary care center. Med J Armed Forces India. 2016; 710: 1-5.

12. Arciola, C. R., Campoccia, D., Ravaioli, S., et al. Polysaccharide intercellular adhesin in biofilm: structural and regulatory aspects. Front Cell Infect Microbiol. 2015; 5: 1-10

13. Cho, S.H., Naber, K., Hacker, J., et al. Detection of the icaADBC gene cluster and biofilm formation in Staphylococcus epidermidis isolates from catheter-related urinary tract infections. Int J Antimicrob Agents. 2002; 19: 570-575

14. Christensen, G. D., Simpson, W. A., Yonger, J. J., et al. Adherence of coagulase-negative staphylococci to plastic tissue culture plates: a quantitative model for the adherence of staphylococci to medical devices. J Clin Microbiol. 1985; 22: 996-1006.

15. Freeman, D. J., Falkiner, F. R., and Keane, C. T. New method for detecting slime production by coagulase negative staphylococci. J Clin Pathol. 1989; 42: 872-874.

16. Heilmann, C., Schweitzer, O., Gerke, C., et al. Molecular basis of intercellular adhesion in the biofilm-forming Staphylococcus epidermidis. Mol Microbiol. 1996; 20: 1083-1091

17. Bauer, A. W., Kirby, W. M. M., Sherris, J. C., et al. Antibiotic Susceptibility Testing by a Standardized Single Disk Method. Am J Clin Pathol. 1966; 45: 493-496.

18. Clinical and Laboratory Standards Institute Performance standards for Antimicrobial Susceptibility; Twenty-Fourth informational supplement, 2014 Philadelphia

19. Rodrigues, L. B., Santos, L. R. D., Tagliari,V. Z. et al. Quantification of biofilm production on polystyrene by Listeria, Escherichia coli and Staphylococcus aureus isolated from a poultry slaughterhouse. Braz J Microbiol. 2010; 41: 1082-1085.

20. Stepanovic, S., Vukovi, D., Hola, V., et al. Quantification of biofilm in microtiter plates: overview of testing conditions and practical recommendations for assessment of biofilm production by Staphylococci. APMIS. 2007; 115 (89): 1-9.

21. Poulsen, A. B., Skov, R., and Pallesen, L. V. Detection of Methicillin Resistance in Coagulasenegative Staphylococci and in Staphylococci Directly from Simulated Blood Cultures Using the EVIGENE MRSA. J Antimicrob Chemother. 2003. 51: 419

22. Yazdani, R., Oshaghi, M., Havayi, A., et al. Detection of icaAD Gene and Biofilm Formation in Staphylococcus aureus isolates from wound infections. Iranian J Publ Health 2006; 35: 2528.

23. Sanger, F., Nicklen, S., and Coulson, A. R. DNA sequencing with chain-terminating inhibitors. Proc Natl Acad Sci USA. 1977; 74: 5463-5467

24. Altschul, S. F., Gish, W., Miller, W., et al. Basic local alignment search tool. J Mol Biol. 1990; 215 (3): 403-410.

25. Shah, D. A., Wasim, S., and Abdullah, F. E. 
Comparison of Oxacillin and Cefoxitin for the Detection of mecA Gene to Determine Methicillin Resistance in Coagulase Negative Staphylococci (CoNS). Journal of the College of Physicians and

Surgeons Pakistan. 2017; 27 (8): 520-522.
26. Oliveira, A., and Cunha, M. L. R. S. Comparison of methods for the detection of biofilm production in coagulase-negative staphylococci. BMC Res Notes. 2010; 3: 260

27. Igbinosa, E. O., and Beshiru, A. Characterization of antibiotic resistance and species diversity of staphylococci isolated from apparently healthy farm animals. Afr J Clin Exper Microbiol. 2019; 20 (4): 289-298

28. Marsik, F. J., and Brake, S. Species Identification and Susceptibility to 17 Antibiotics of CoagulaseNegative Staphylococci Isolated from Clinica Specimens. J Clin Microbiol. 1982; 15: 640 - 645

29. Javadpour, S., Karimi, E., and Karmostaji, A. Frequency and antibiogram pattern of coagulase negative Staphylococcus in clinical specimens of Shahid Mohammadi Hospital in patients, BandarAbbas, Iran. Afr J Microbiol Res. 2010; 4 (14): 1581-1583.

30. Goudarzi, M., Seyedjavadi, S., Goudarzi, H., et al. Characterization of coagulase-negative staphylococci isolated from hospitalized patients in Tehran, Iran. Journal of Paramedical Sciences. 2014; 5 (2): 44-50.

31. Iorio, N. L. P., Azevedo, M. B., Frazão, V. H., et al. Methicillin resistant Staphylococcus epidermidis carrying biofilm formation genes: detection of clinical isolates by multiplex PCR. Int Microbiol. 2011; 14: 13-17.

32. Pinna, A., Zanetti, S., Sotgiu, M., et al. Identification and antibiotic susceptibility of coagulase negative staphylococci isolated in corneal/external infections. $\mathrm{Br} \mathrm{J}$ Ophthalmol. 1999; 83: 771-773.

33. Pinheiro, L., Mello, P. L., Abraao, L. M., et al. Evaluation of reference values for phenotypic tests to detect oxacillin resistance in coagulasenegative staphylococci. Future Microbiol. 2018; 13 (5): 565-575.

34. Courvalin, P., Leclercq, R., et Bingen, $E$. Antibiogramme. Annexe. $2^{\mathrm{e}}$ édition ESKA; 2006.

35. Jain, A., Agarwal, J., and Bansal, S. Prevalence of methicillin-resistant, coagulase negative staphylococci in neonatal intensive care units: findings from a tertiary care hospital in India. ] Med Microbiol. 2004; 53: 941-944.

36. Boukhatem, M. N., Ferhat, M. A., Mohamed, H. et al. Prevalence and antibiotic resistance of Staphylococci isolated from Kolea Hospital, Algeria. Journal of Fundamental and Applied Sciences. 2015; 7 (2): 260-270.

37. Farid, A., Naz, I., Ashraf, A., et al. Molecular detection of antimicrobial resistance in local isolates of Staphylococcus epidermidis from urinary tract infections in Faisalabad region of Pakistan. EXCLI Journal. 2015; 14: 697-705.

38. Gatermann, S. G., Koschinski, T., and Friedrich, S. Distribution and expression of macrolide resistance genes in coagulase-negative staphylococci. Clin Microbiol Infect. 2007; 13: 777-778.

39. Nasr, R. A., AbuShady, H. M., and Hussein, H. S. Biofilm formation and presence of icaAD gene in clinical isolates of staphylococci. The Egyptian Journal of Medical Human Genetics. 2012; 13: 269-274.

40. Becker, K., Heilmann, C. and Peters, G. Coagulase-Negative Staphylococci. CMR. 2014; 27: $870-926$ 